\title{
Dr. Strangelove, or how I learned to stop worrying and love the core competencies
}

\author{
Mitchell S.V. Elkind, MD, MS, FAAN
}

$\mathbf{S}$ wallow hard. If you are a neurology residency program director, plan to be one, or spend considerable amounts of time around one, you may feel that you are in for a rough ride over the next couple of years. New work hours restrictions imposed by the Accreditation Council on Graduate Medical Education (ACGME) have created significant strains on our system of providing neurologic education, leading to a fair amount of debate in the graduate medical education community. New ACGME requirements regarding teaching and evaluating core competencies provide another burden and challenge. The core competencies, moreover, are relevant not just to residency education, but to practicing neurologists, as they are to be incorporated into continuing medical education, board certification, and credentialing. But while the core competencies initially struck me as abstruse and burdensome, the difficulties they engender are, on reflection, readily surmountable. In my case, a helpful approach to the competencies began with the recognition that we were already doing most of the things the ACGME asked for, though we may not have labeled them as such.

\section{What are the core competencies?}

The core competencies are the six general areas of competence in medical practice that all residents, in every specialty, are expected to learn and that faculty members are therefore expected to teach and evaluate. Neurology has specific competencies that reflect our particular field, but these all fall within one of the six general categories. The shift toward competencies is viewed by the ACGME as a fundamental (even revolutionary) change in medical education and reflects a move to a competence-based rather than time-based approach to medical residency training. Whereas in past years, residents were expected and assumed to have achieved competence in their field simply by being present in a residency program and completing certain time-linked rotations (e.g., a month in the neurointensive care unit), the goal now is clear demonstration and documentation of a professional level of ability in each of these six core areas. The rationale for the core competencies and the contents of each as they apply to neurology have been thoroughly reviewed in a book published by the American Board of Psychiatry and Neurology (ABPN). ${ }^{1}$ In brief, the general categories of competence are as follows:

1. Patient Care

2. Medical Knowledge

3. Interpersonal Skills and Communication

4. Practice-Based Learning and Improvement

5. Professionalism

6. Systems-Based Practice
The first two of these, Patient Care and Medical Knowledge, fall within the traditional sphere of resident education, and most neurology residency programs already do a pretty good job of evaluating them: mock boards, Residency InService Training Exam, written evaluations, quizzing residents on rounds (also known as "pimping"), and other methods.

The latter four competencies appeared a lot more nebulous to me, however. How does one teach or evaluate Professionalism? What on earth do they mean by SystemsBased Practice? But after my initial frustration subsided, and I had survived my first couple of years of program directorship, I could see that our program was already teaching and evaluating these items implicitly, although most of our faculty members were not aware of it. A simple approach to addressing the core competencies, I realized, would be to make more explicit what we were already doing.

\section{Principles for painless \\ incorporation of core competencies into residency training}

As I began to tackle incorporating the competencies into our program, I found it helpful to define several principles that could rationally guide the process. It seemed to me that incorporation of the core competencies should-and can-be accomplished at minimal cost to al- 
ready overburdened residents and residency program directors. The intent of ACGME's new emphasis on core competencies, after all, was surely not to make additional work for program administrative staff (although initially this thought did cross my mind), but rather to improve the quality of education and the competence of practicing neurologists. My principles were the following:

1. Minimize resident burden. The evaluation process should add minimally to the workload of individual residents, as residents are generally already extremely busy, and work hour limits have eroded any additional time available for completing logs, surveys, and other materials required to demonstrate competence. The newly introduced Neurology Residency Review Committee's resident case log system could be an example of a minimally burdensome addition to the demonstration of competence, if, in fact, only 1 minute is required per patient entered into the system

2. Minimize administrative burden. The evaluation process should add minimally to the burden of the administrative staff (residency program directors and residency coordinators), as no support for additional educational and evaluative activities has been provided by residency funding sources. (It was around this time that "unfunded mandates" became one of my favorite expressions.)

3. Real-life situations. The evaluation process should utilize real-life clinical opportunities to the greatest extent possible, rather than introduce artificial elements. I believed that our program's clinical load was large enough that it would be most efficient to utilize real patients in the process rather than, say, actors. This would limit the amount of additional time and work for residents, faculty, and administrative staff. In some instances, standardized materials or artificial situations may be of benefit (e.g., mock oral boards), but these should be used on a limited basis.
For example, we perform mock oral boards annually.

4. The teachable moment. Use existing meetings, conferences, and committees when possible. Many of the competencies lend themselves to teachable moments that occur commonly in the course of routine resident gatherings and meetings. At our monthly resident meetings, issues related to practice and hospital systems frequently arise, such as medical record completion, hospital initiatives to improve documentation, and optimal ways to structure rotations to maximize efficiency. Residents and faculty may not recognize these as examples of resident education in the core competencies, but they can easily serve this function. By involving residents in committees focused on these issues, moreover, we also have occasion to evaluate their competence in these areas. For example, we recently formed a subcommittee of residents and faculty members to create a protocol that defines when junior residents must seek assistance from more senior residents or attendings. Active participation in this committee was an opportunity for residents to demonstrate competence in Practice-Based Learning and Improvement, Professionalism, and Systems-Based Practice. Morbidity and mortality conferences also provide obvious settings to address Practice-Based Learning and Improvement and Professionalism.

5. Maximize educational value. The evaluation process should seek to simultaneously maximize educational value as it evaluates. Mock oral boards, for example, when done properly with immediate feedback, often function as educational sessions as much as evaluative ones.

\section{Specific methods of evaluating the core competencies}

According to the ACGME's director, David Leach (personal communication), the elements critical to demonstrating full compliance with the mandate to evaluate core competencies are threefold: 1) personal observation, 2) $360^{\circ}$ evaluations, and 3) portfolios.

Detailed descriptions of these and other competency evaluation tools can be found on the ACGME Web site (www.acgme.org/outcome/ assess/toolbox). Program directors and faculty members involved in education of residents will also gain a better appreciation of the methods for evaluation of core competencies that will be expected of them when the site visit comes around by reviewing the new on-line General Competencies Addendum to the Program Information Form. This addendum provides examples of several different methods of evaluation and asks for brief descriptions of up to eight different ways the program is evaluating the competencies. This document is a good example of why it is never too early to begin preparing for the next site visit!

Currently, it is expected that programs will begin to address the core competencies in their curricula and evaluation tools. There is no absolute requirement that programs do one thing or another, and there is no consensus on what works. Going forward, therefore, it will be important for the neurologic community, and in particular its organized groups of educators, such as chairpersons and program directors, to share their successes and failures at meetings and in publications. The ACGME now sponsors meetings addressing evaluation of competencies, and the American Academy of Neurology has sponsored similar courses, as well as less formal discussions, at its annual meeting. The Consortium of Neurology Program Directors is another resource for sharing experiences with these evaluation tools. By combining forces, it is hoped, programs may avoid duplicative efforts at testing methods.

Following are brief descriptions and personal comments regarding these three key methods.

1. Personal observation. Faculty document their observation of residents performing various tasks such as examining patients, 
doing procedures, interpreting radiologic studies, etc. These observations can be incorporated into the usual end-of-rotation global evaluations that most programs already have attending physicians complete.

2. $360^{\circ}$ evaluations. These are evaluations not only by faculty, but also by others in a better position to observe certain aspects of a resident's performance, including nurses, co-residents, patients, self, and others. Theoretically, by incorporating a broader spectrum of opinions, $360^{\circ}$ evaluations better capture competence in Interpersonal Skills and Communication, Professionalism, and Systems-Based Practice. Evaluations collected from patients and busy primary nurses would create an undue burden on our administrative staff, however, since heroic efforts would likely be needed to retrieve the evaluations consistently. Attempts to validate such evaluations or to demonstrate their utility would be a major project, moreover, and one for which we do not have funding. While $360^{\circ}$ evaluations have been found useful in the business community, experience in residency education remains limited to a few pilot projects, ${ }^{2-4}$ which have found some benefit but at tremendous cost. ${ }^{5}$ Methodologic issues also include the finding that sicker patients tend to give their physicians lower scores $^{6}$ and the fact that patients may have language barriers and limited access to computers to enter results. Although systematic research into the optimal way to conduct these evaluations is ongoing, several questions remain unanswered: Who should evaluate? How often? What should be done with the information? Evaluators and instruments will also likely need to be different across specialties. What works in surgical or emergency medicine programs may not be relevant to neurology practice, either, with its greater emphasis on chronic care and cognitively impaired patients. For these reasons, no consensus has been reached on an approach to the $360^{\circ}$ evaluation in neurology.

Nonetheless, in our program, incorporation of a limited number of additional evaluators with knowledge of different aspects of residents' performance into the process has provided unique information and was accomplished with minimal effort. We have found it useful, for example, to include reports from our nursepractitioners, who work closely with the residents and take signout from post-call residents every day. The nurse-practitioner evaluations include information about quality of sign-out (relevant to competence in Interpersonal Skills and Communication) and interactions with therapists and support staff (relevant to competence in Systems-Based Practice). Resident self-assessments have provided the opportunity for residents to reflect on their strengths and weaknesses and to focus their educational goals and objectives (relevant to competence in Professionalism). Based on the administrative cost of retrieving more extensive evaluations from other team members and patients, I believe it is reasonable to expect that proscriptive requirements for the use of more complete $360^{\circ}$ evaluations (including patients, patients' families, floor nurses, radiology technicians, and others) would follow completion of rigorous, systematic studies demonstrating the benefits to residency outcomes and competence. Until such studies are done, a reasonable compromise is for programs to incorporate into the evaluation system those individuals with whom the resident interacts that are most likely to provide obviously useful information.

3. Portfolios. Portfolios are resident compilations of experiences encountered during residency. These would include diagnoses encountered and procedures performed but may also include, as we have begun to do, other experiences including lectures given and conferences led, medical errors and responses to these, literature searches, research projects, papers written, books and papers read, major meetings attended, and even personal milestones achieved during residency. Participation in departmental or hospital committees would also fit in here. These experiences can be easily kept in a binder or, potentially, an on-line recording system.

It should be recognized, however, that case logs and other systems for listing experiences do not in themselves guarantee competence: Seeing 25 cases of Parkinson disease does not in itself ensure that a resident will care for those patients appropriately. Determination of competence in caring for these patients will ultimately depend on a combination of logs with the other methods, like observation and well-rounded evaluations. But logs can serve to provide evidence of an appropriate breadth of experience for residents, a minimum exposure to all the important areas of neurology. Those residents whose case logs demonstrate lacunae in experience (only a few cases of Parkinson disease during the first 2 years of residency, for instance) may need to be directed toward future rotations in which they can increase their exposure to certain disease conditions or procedures. Similarly, programs can use their residents' logs in aggregate to evaluate the program's overall breadth of experience; if no one in the program is seeing enough multiple sclerosis (MS), then the program may need to send residents to rotations at other institutions where MS is seen more often or introduce other ways of broadening their exposure.

\section{Core competencies: Not just for residents anymore!}

It is important to recognize that the core competencies are not just relevant to residency education, moreover. They are increasingly being applied to continuing medical education, board certification, and credentialing. The ABPN has emphasized that the core competencies will be incorporated into maintenance of certification, as well. Core competencies are likely 
to be important even as neurologists move into the later stages of their careers. We thus have a choice: either to fight a quixotic battle against core competencies, or, recognizing that we are, in fact, already utilizing them, incorporate them into everyday teaching and practice in ways that minimize any additional burden.

And, remember, that which does not kill us can only make us stronger!

\section{Acknowledgment}

The author thanks Dr. Timothy A. Pedley and Rachel Vail for reviewing earlier drafts of the manuscript.

\section{References}

1. Scheiber SC, Kramer TAM, Adamowski SE. Core competencies for neurologists: what clinicians need to know. Philadelphia: Butterworth Heinemann, 2003.

2. Rodgers KG, Manifold C. 360-degree feedback: possibilities for assessment of the ACGME core competencies for emergency medicine residents. Acad Emerg Med 2002;9: 1300-1304.

3. Higgins RSD, Bridges J, Burke JM, O'Donnell MA, Cohen NM, Wilkes SB. Imple- menting the ACGME general competencies in a cardiothoracic surgery residency program using 360-degree feedback. Ann Thorac Surg 2004;77:12-17.

4. Joshi R, Ling FW, Jaeger J. Assessment of 360-degree instrument to evaluate residents' competency in interpersonal and communication skills. Acad Med 2004;79:458-463.

5. Brasel KJ, Bragg D, Simpson DE, Weigelt JA. Meeting the Accreditation Council for Graduate Medical Education competencies using established residency training program assessment tools. Am J Surg 2004; 188:9-12

6. Duffy FD, Gordon GH, Whelan G, Cole-Kelly K Frankel R. Assessing competence in communication and interpersonal skills: The Kalamzoo II Report. Acad Med 2004;79:495-507. 


\section{Neurology}

\section{Dr. Strangelove, or how I learned to stop worrying and love the core competencies Mitchell S.V. Elkind}

Neurology 2005;64;E3-E6

DOI 10.1212/01.WNL.0000148857.55477.0F

This information is current as of January 24, 2005

\section{Updated Information \&} Services

References

Citations

Permissions \& Licensing

Reprints including high resolution figures, can be found at: http://n.neurology.org/content/64/2/E3.full

This article cites 5 articles, 0 of which you can access for free at: http://n.neurology.org/content/64/2/E3.full\#ref-list-1

This article has been cited by 1 HighWire-hosted articles: http://n.neurology.org/content/64/2/E3.full\#\#otherarticles

Information about reproducing this article in parts (figures,tables) or in its entirety can be found online at:

http://www.neurology.org/about/about_the_journal\#permissions

Information about ordering reprints can be found online:

http://n.neurology.org/subscribers/advertise

Neurology ${ }^{\circledR}$ is the official journal of the American Academy of Neurology. Published continuously since 1951, it is now a weekly with 48 issues per year. Copyright . All rights reserved. Print ISSN: 0028-3878. Online ISSN: 1526-632X.

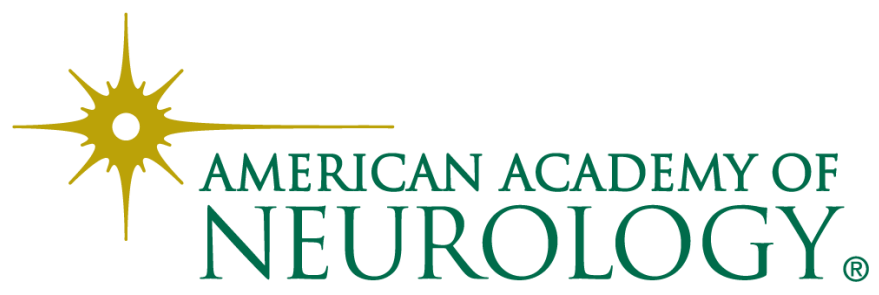

